\title{
Pengaruh Hubungan Orangtua-Anak terhadap Kepercayaan antar Pribadi yang di moderasi oleh Kedekatan dengan Teman Sebaya pada siswa SMA
}

\author{
Haryanti Tri Darmi Titisari \\ University of Muhammadiyah Malang \\ Email : ning.iip81@gmail.com
}

\begin{abstract}
High school students in the adolescence development are influenced by several factors including the environment in physical and psychological development. Attachment to family and friends has an important role in the establishment of trust, including the Interpersonal Trust. Based on that, this study aims to determine the influence of parent and child attachment to interpersonal trust that is moderated by individual attachment to peers. The subjects in this study were high school students on grade $12^{\text {th }}$ as many as 99 students. The study utilized the scale of Parent-Child Relationship, Interpersonal Trust and IPPA, and applied statistics with multiple linear regression techniques. This study shows that Parent and Child Relationship was negatively correlated with Interpersonal Trust, with correlation coefficient of -0.111 and significance value of $0.275(p>0,05)$, indicating that the greater the parent relationship with the child, the less Interpersonal Trust, and vice versa. Nevertheless, the analysis results show that the Moderation Variable (Peer Attachment) was influential, and able to strengthen the relationship between parent and child to Interpersonal Trust.
\end{abstract}

Keywords : Parent-Child Relationship, Interpersonal Trust, Peer Attachment

\section{PENDAHULUAN}

Persahabatan merupakan konteks yang sangat penting terutama selama masa remaja, untuk pengembangan kedua individu dalam sikap dan manifestasi perilaku yang sifatnya membangun (Hartup 1996; Piehler and Dishion 2007). Individu dengan pengendalian diri yang tinggil lebih memahami kualitas dan intensitas dalam hubungan persahabatan (John H. Boman IV, et all, 2012). Barakat, A. \& Othman, A. (2015) menyatakan bahwa interaksi orang tua dan anak merupakan prediktor dalam kualitas hubungan persahabatan pada remaja. Bukowski (Parker \& Asher, 1993) yang menyebutkan ciri-ciri persahabatan yang berkualitas adalah adanya hubungan kesejatian yang terkandung dalam ketulusan, kejujuran, dan lain sabagainya. Dalam sebuah penelitian yang dilakukan oleh Saric dan Sakic (2014) yang menyoroti pentingnya peran orang tua dan teman-temannya yang mendorong perkembangan positif dalam masa remaja.

Penelitian lebih lanjut menunjukkan kedua orang tua dan teman-temannya berpengaruh pada anak dan hasil penyesuaian remaja. Kualitas persahabatan memiliki efek positif orangtua pada internalisasi gejala dari waktu ke waktu. Obiunu (2015), mengukur praktek orangtua dan Jaringan persahabatan remaja, hasilnya menunjukkan bahwa orang tua memiliki kapasitas dalam membentuk karakteristik jaringan persahabatan pada anak mereka, bahkan setelah mempertimbangkan kemungkinan bahwa remaja memiliki 
teman yang mirip dengan diri mereka sendiri. Carol Dweck dalam penelitiannya berpendapat bahwa "pandangan kita dalam mengadopsi peran untuk diri sendiri sangat berpengaruh pada cara kita dalam menjalani hidup" (Dweck, 2006: 6).Kualitas persahabatan, Rekan grup afiliasi, dan rekan anti perilaku sosial sebagai moderator terhadap hubungan antara orangtua yang negatif dan perilaku eksternalisasi remaja.

Keterlibatan orang tua juga menyebabkan hubungan yang baik antara anak dan teman-temannya (misalnya, Smith \& Hubbard, 1988), dan komunikasi yang baik antara staf dan orang tua dianggap prasyarat untuk pengasuhan yang berkualitas tinggi dalam pendidikan anak-anak (DohertyDerkowski, 1995, Hughes \& MacNaughton, 2000). Orang tua memiliki tanggung jawab yang utama dalam mengontrol perkembangan anak dan meiliki peranan penting dalam keberhasilannya (Bernheimer, Gallimore, \& Weisner, 1990; Guralnick, 1989). Sedangkan masa remaja merupakan masa dimana individu akan mengisi kehidupannya dengan proses pencarian jati diri dan menghabiskan waktunya lebih banyak dengan temantemannya daripada dengan orang tuanya (Besger, 2007). Greenberg \& Armsden (2007) menyebutkan beberapa aspek yang mempengaruhi kelekatan/ kedekatan dengan teman sebaya yaitu: Komunikasi (Communication), Kepercayaan (Trust), dan Keterasingan (Alienation). Kualitas kedekatan dengan teman sebaya dapat membantu individu untuk menjalin hubungan yang positif dan empatik dengan orang lain (Motta \& Matos, 2012)

Hubungan individu secara manusiawi dibentuk oleh aktualisasi kualitas pribadi, yang merupakan tingkat hubungan interpersonal. Dengan hubungan interpersonal, individu mampu mewujudkan pengembangan pribadi dari proses belajar yang muncul melalui interaksi sosial (Elena \& Anton, 2016). Interaksi sosialnya yaitu dengan lingkungan sekitarnya termasuk keluarga sebagai lingkungan yang paling dekat dan teman-teman sebaya. Hubungan interpersonal sebagai timbal balik kesiapan seseorang dalam berkomunikasi dengan cara tertentu, seperti hubungan yang disertai dengan saling memahami, pengertian, dan saling peduli (Obozov, 1979). Dengan demikian, interpersonal trust dapat dianggap sebagai sistem koneksi batin seseorang dengan lingkungan dalam bentuk sensasi dan tindakan yang menjadi pandangan seseorang dalam penghargaan atas hak asasi dan martabat manusia, untuk nilainilai kemanusiaan, tanggap, hubungan manusiawi, empati, ketegasan, dan sebaginya, baik dalam diri sendiri dan orang lain (Kleptsova, 2013).

Berdasarkan uraian diatas, maka hipotesis dalam penelitian ini adalah ada pengaruh antara hubungan Orang tua dan anak (Parent-Child Relationship) terhadap kepercayaan antar pribadi atau teman (Interpersonal Trust), dan variabel moderasi (Kedekatan dengan teman sebaya/ Peer Attachment) mampu memperkuat hubungan antara kedua variabel tersebut (Parent-Chil Relationship dan Interpersonal Trust).

\section{METODE}

Penelitian ini menggunakan analisis regresi linear berganda. Analisa data yang digunakan adalah statistik dengan tehnik korelasi dan diolah menggunakan komputer dengan berdasar pada tujuan penelitian yaitu untuk membuktikan pengaruh hubungan Orangtua dan anak terhadap Kepercayaan antar pribadi yang dimoderasi oleh kelekatan dengan teman sebaya pada siswa SMA Muhammadiyah I Jombang.

Subjek pada penelitian ini adalah siswa SMA Muhammadiyah Jombang yang berjumlah 113 siswa sedangkan 
yang hadir adalah 99 siswa. Arikunto (2006) berpendapat bahwa apabila subjek penelitian kurang dari 100, lebih baik diambil semuanya sehingga penelitiannya merupakan penelitian populasi, selanjutnya jika jumlah subjeknya lebih dari 100 maka diambil antara $10 \%-20 \%$ atau $20 \%-30 \%$ atau lebih. Dengan demikian berdasarkan pendapat tersebut, ukuran sampel yang dipilih dalam penelitan ini adalah seluruh siswa yang hadir yang berjumlah 99 siswa yang terdiri dari 66 siswi dan 33 siswa dengan usia sekitar 15-19 tahun.

Pada penelitian ini, tehnik pengumpulan datanya menggunakan Kuisioner dan disusun berdasarkan Modifikasi Skala Likert (Method of Summated Rating) yang berupa pernyataan tertutup dimana subjek diminta untuk memilih 4 alternatif pilihan jawaban yaitu Sangat Setuju, Setuju, Tidak Setuju, Sangat Tidak Setuju dengan pemberian skor sebagai berikut : (1) Pernyataan yang mendukung penelitian (Favourable): Sangat Setuju (nilai 4), Setuju (nilai 3), Tidak Setuju (nilai 2), Sangat Tidak Setuju (nilai 1); (2) Pernyataan yang tidak mendukung penelitian (Unfovourable): Sangat Setuju (nilai 1), Setuju (nilai 2), Tidak Setuju (Nilai 3), Sangat Tidak Setuju (Nilai 4)

Maksud dari kategori tersebut adalah untuk melihat kecenderungan pendapat dari responden ke arah Selalu atau Tidak Pernah. Contoh aitem pada masing skala yaitu, sebagai berikut : (1) Parent-Child Relationship Scale, "Saya biasanya bermain bersama dengan orangtua saya"; (2) Interpersonal Trust Scale, "Dalam berinteraksi dengan orang yang belum dikenal, sebaiknya kita berhati-hati sampai mereka bisa kita percaya"; (3) Inventory of Parent and Peer Attachment, "Saya senang mendapatkan nasehat dari teman tentang hal-hal yang sedang saya lakukan"

Azwar S. (1999) berpendapat bahwa analisis validitas dilakukan dengan menghitung koefisien korelasi antara distribusi skor item dan distribusi skor test atau total. Cronbach (Azwar S., 1999) menyatakan bahwa dalam proses validitas tes, sebetulnya tidak bertujuan untuk melakukan validitas tes, tetapi interpretasi dari yang diperoleh dengan prosedur tertentu. Uji validitas dilakukan dengan mengkorelasikan nilai setiap item dengan skor total dan menggunakan tehnik analisa Product Moment, dan dalam perhitungan validitasnya, peneliti menggunakan program SPSS. Reliabilitas adalah indeks yang menunjukkan kemampuan alat ukur yang dapat dipercaya atau dapat diandalkan. Azwar S. (1999) menyatakan bahwa reliabilitas adalah sejauhmana hasil pengukuran dapat dipercaya.

\section{HASIL}

Penelitian ini menggunakan kuisioner sebagai alat ukur yang disebar kepada seluruh siswa kelas XII SMA Muhammadiyah I Jombang. Pada uji validitas mengguanakan nilai minimal 0,300 sehingga bisa dikatakan valid $(\mathrm{p}=0,000)$ karena rhitung > rtabel. Berdasarkan hasil analisis tersebut, pada angket Parent-Child Relationship didapat 32 aitem yang valid dan 2 aitem yang gugur dengan nilai Croanbach alpha $(\alpha)$ 0,930 . Selain itu pada kuisioner Interpersonal Trust dihasilkan 8 aitem yang dinyatakan valid dan 17 aitem yang gugur dengan nilai Croanbach alpha $(\alpha)$ 0,673 . Sedangkan pada angket Peer Attachment terdapat 17 aitem yang valid dan 8 aitem yang gugur dengan nilai alpha $(\alpha) 0,913$ dari Croanbach.. Pada uji normalitas, variabel $\mathrm{X}$ (Parent-Child Relationship) memiliki nilai absolute $(p=0,200)$ yang berarti bahwa variabel bebasnya normal, namun memiliki nilai absolute $\quad(\mathrm{p}=0,034)$ untuk Peer Attachment dan $(\mathrm{p}=0,008)$ pada Interpersonal Trust. Dengan demikian kedua variabel tersebut (Variabel Moderasi dan Variabel Terikat) tidak normal karena nilai $\mathrm{p}<0,05$. Demikian halnya pada uji linearitas, menghasilkan 
linearity dengan nilai $\mathrm{p}=0,206$ (ParentChild Relationship) dan $\mathrm{p}=0,180$ (Peer Attachment) sehingga pengaruh variabel (X dan $\mathrm{M}$ ) dalam penelitian tersebut dikatan tidak linear karena $\mathrm{p}>0,05$.

Data yang sudah terkumpul dalam penelitian, dijadikan sebagai bahan pertimbangan dalam mengambil keputusan. Hasil analisis moderasi dari variabel Parent-Child Relationship (X), Peer Attachment (M), dan Interpersonal Trust (Y) dapat disimpulkan bahwa terjadi moderasi yang signifikan. Hal ini dibuktikan pada nili signifikansi yang menghasilkan 0,000 yang lebih kecil dari 0,05 yang merupakan standard nilai signifikansi $(p=0,000<0,05)$. Berdasarkan hasil analisis tersebut, terdapat beberapa hasil yang menunjukkan bahwa Parent-Child Relationship tidak dapat memprediksi Interpersonal Trust secara signifikan karena variabel Parent-Child Relationship dan variabel Interpersonal Trust memiliki persaamaan regresi yang ditunjukkan nilai $\mathrm{R}$ (koefisien regresi) sebesar 0,111 dengan nilai signifikansi sebesar $p=0,275>0,05$. Hasil berikutnya menunjukkan bahwa variabel (Peer Attachment) juga tidak dapat memprediksi variabel (Interpersonal Trust) secara signifikan. Hal ini ditunjukkan pada variabel keduanya dengan nilai $\mathrm{R}$ (koefisien regresi) sebesar 0,216 dan nila $\mathrm{R}$ Square 0,047 dengan nilai signifikansi sebesar $p=0,066>$ 0,05 . Namun, ketika variabel moderasi dimasukkan, memiliki nilai $\mathrm{R}$ (koefisien regresi) sebesar 0,447 dan nilai $\mathrm{R}$ square 0,200 serta memberikan sumbangan sebesar $20 \%$ dengan nilai signifikansi ( $\mathrm{p}$ $=0.000<0.05$ ). Hal ini di tunjukkan pada Tabel 1 di lampiran.

Dengan demikian, ketiga hasil tersebut dapat disimpulkan bahwa penelitian ini menunjukkan Hubungan Orangtua dan Anak berkolerasi negatif dengan Interpersonal Trust, dengan nilai koefisien korelasi sebesar -0,111 dan nilai signifikansi 0,275 ( $p>0,05)$, yang menunjukkan bahwa semakin besar hubungan orangtua dengan anak maka semakin kecil kepercayaan antar pribadi (Interpersonal Trust), begitu juga sebaliknya. Namun variabel Moderasi (Peer Attachment) memiliki pengaruh dan mampu memperkuat hubungan antara Parent-Child Relationship dengan Interpersonal Trust. Hal ini ditunjukkan pada Tabel 2 di lampiran.

Hasil penelitian ini dapat disimpulkan bahwa tidak ada pengaruh yang signifikan antara Hubungan Orangtua dan Anak (Parent-Child Relationship) terhadap kepercayaan antar pribadi atau teman (Interpersonal Trust) dan hipotesis yang pertama ditolak. Namun, Hubungan kedekatan dengan teman sebaya (Peer Attachment) yang merupakan variabel moderasi, mampu memperkuat hubungan antara variabel $\mathrm{X}$ (Parent-Child Relationship) dengan variabel Y (Interpersonal Trust), sehingga dengan demikian Hipotesis kedua diterima.

\section{DISKUSI}

Tujuan dalam penelitian ini adalah untuk mengetahui pengaruh kedekatan orangtua dan anak terhadap kepercayaan antar personal yang dimoderasi oleh kedekatan individu dengan teman sebaya. Setelah melakukan pengolahan data, hasil penelitian menunjukkan bahwa tidak ada pengaruh hubungan orangtua dan anak terhadap kepercayaan antar pribadi yang signifikan, namun hubungan kedekatan dengan teman sebaya mampu memperkuat hubungan antara Parent-Child Relationship dengan Interpersonal Trust. Hal ini bisa dipengaruhi oleh beberapa aspek, seperti pendapat Besger (2007) yang menyatakan bahwa masa remaja merupakan masa dimana individu akan mengisi kehidupannya dengan proses pencarian jati diri dan menghabiskan waktunya lebih banyak dengan temantemannya daripada bersama dengan orangtuanya. Begitu juga dengan Motta 
\& Matos (2012) yang berpendapat bahwa kualitas kedekatan dengan teman sebaya mampu membantu individu dalam menjalin hubungan yang positif dan empatik dengan orang lain (Interpersonal Trust).

Menjalin hubungan kedekatan dengan teman atau biasa kita sebut dengan sahabat, mampu memperkuat interaksi sosial pada individu baik itu hubungan dengan lingkungan sekitar seperti orangtua dan lingkungan sosialnya yang merupakan faktor dari luar, maupun faktor yang timbul dari dalam diri seperti tumbuhnya rasa kepercayaan antar pribadi (Interpersonal Trust), karena persahabatan merupakan hubungan pribadi yang menyangkut keseluruhan pribadi yang berdasar pada kepercayaan yang mendalam dengan saling membagikan atau memberikan sesuatu, menerima sesuatu, dan merupakan kesempatan untuk memperluas diri (Mussen, dkk; 1980). Grinder (1978) dan Parker \& Asher (1993) menyebutkan ciri-ciri dalam persahabatan adalah adanya kesejatian (ketulusan, kejujuran, kesetiaan, kepercayaan dan kehangatan pribadi), keterbukaan diri, kesamaan (seperti pendidikan, usia, pandangan hidup, sikap, dan lain-lain), dan adanya kebersamaan. Dan H. Fuad (2008) menyebutkan bahwa persahabatan memiliki fungsi agar terhindar dari alienasi (perasaan terasing dari lingkungan sosialnya),selain itu persahabatan juga mampu memberikan dukungan emosi serta kesempatan untuk pengembangan kepribadian dan pengembangan ketrampilan sosial.

\section{SIMPULAN}

Berdasarkan hasil pengolahan data pada penelitian ini, maka dapat disimpulkan bahwa tidak ada pengaruh yang signifikan antara hubungan orangtua dan anak terhadap kepercayaan antarpribadi atau teman pada siswa kelas XII Sekolah Menengah Atas
Muhammadiyah 1 Jombang. Meskipun demikian, peneliti berharap ada penelitian-penelitian berikutnya yang meneliti dan membahas variabel-variabel lain yang lebih berpengaruh dan berhubungan dengan Interpersonl Trust, karena banyak faktor yang mengindikasikan memiliki peranan penting pada Interpersonal Trust individu, baik itu faktor dari dalam maupun faktor luar seperti pengaruh lingkungan sekitar, dalam hal ini lingkungan keluarga, sekolah dan terutama hubungan dengan teman sepermainan.

\section{DAFTAR PUSTAKA}

Azwar, Saifuddin. (1999). Reliabilitas dan Validitas Cetakan Ketiga. Yogyakarta:Pustaka Belajar.

Arikunto, S. (2006). Prosedur Penelitian Suatu Pendekatan Praktik. Jakarta: PT. Rineka Cipta.

Barakat, A. \& Othman, A. The FiveFactor Model of Personality and Its Relationship to Cognitive Style (Rush and Prudence) and Academic Achievement Among a Sample of Student. Vol 6, No. 35, 2015.

Bernheimer, Lucida P.; Gallimore, Ronald; \& Weisner, Thomas S. (1990). Ecocultural Theory as a Context for The Individual Family Service Plan. Journal of Early Intervention, 14(3), 219-233.

Besger, S. K. (2007). Update on Bulliying at School: Science Forgotten? Developmental Review, 27, 90-126.

Hazen, N. (2013). Maternal Empathy and Changes in Mothers' Permissiveness as Predictors of Toddlers' Early Social Competences with Peers: A 
Parenting Intervention Study. Journal Child Family Studies, 22, 769-778.

Doherty-Derkowski, G., 1995. Quality matters: Excellence in early childhood programs. Don Mills, Addison-Wesley Publishers Ltd.

Dweck, C. S. (2006). Mindset: The new psychology of success. New York: Random House.

Guralnick, Michael J. (1989). Recent Development in Early Intervention Efficacy Research: Implications for Family Involvement. Topics in Early Childhood Special Education, 9(3), 1-17.

Greenberg, M. T. \& Armsden, G. (2009). Inventory of Parent and Peer Attachment (IPPA). Prevention Research Center.

Grinder, R. E. (1978). Adolescence. New York:John Wiley and Sons.

Hartup, W. W. (1996). The company they keep: Friendships and their developmental significance. Child Development, 67, 1-13.

H., John., IV, Boman., D., Marvin., Krohn., L., Chris., Gibson., M., John., Stogner. (2012). INVESTIGATING FRIENDSHIP QUALITY: An Expolration of SelControl and Social Control Theories' Frienship Hiphoteses.,2012,012.

Hughes, Patrick, \& MacNaughton, Glenda. (2000). Consensus, Dissensus or Community: The Politics of Parent Involvement in Early Childhood Education. Contemporary Issues in Early Childhood, 1(3), 241-258.

Kleptsova, E.Yu. (2013). Monitoring of the humanization of interpersonal relations in educational activities. Bulletin of the Cherepovets State University, 1 (46). V. 2: 133-135.

Kleptsova, E. Y., \& Balabanov, A. A. (2016). Development of Humane Interpersonal Relationship. International Journal of Environmental \& Science Education. Vol. 11. No. 4, $2147-$ 2157

Mussen, H. P., Cenger, J. J., \& Kagan, J. (1980). Child Development and Personality. New York:Harper and Row Publishers.

Nashori, H. Fuad. (2008). Psikologi Sosial Islami. Bandung:PT Refika Aditama.

Obiunu, Jude J. (2015). Relationship between Parents and Peer Influencences on Qualities of Adolescent Friendship. Journal of Education and Practice. Vol. 6. No.8. 2015.

Obozov, N.N. (1979). Interpersonal relations. Leningrad: Leningrad State University, 6 p.

Parker, J. G. \& Asher, S. R. (1993). Friendship and Friendship Quality in Midle Childhood: Link with Peer Group Acceptance and Feeling of Loneliness and Social Dissatisfaction. Journal of Developmental Psychology, 29, 611-621.

Piehler, T. F., \& Dishion, T. J. (2007). Interpersonal dynamics within adolescent friendships: Dyadic mutuality, deviant talk, and patterns of antisocial behavior. Child Development, 78, 16111624.

Pinheiro Mota, C. \& Matos, P. M. (2012). Peer Attachment, Coping and SelfEsteem in Institutionalized 
Adolescents : The Mediating Role of Social Skills, 28-87.

Raboteg-Saric, Z. \& Sakic, M. Applied. (2014). Relations of Parenting Styles and Friendship Quality to Self-Esteem, Life Satisfaction and Happiness in Adolescents, 9: 749

Smith, Anne B., \& Hubbard, Pat M. (1988). The Relationship between Parent/ Staff Communication and Childdren's Behaviour in Early Childhood Settings. Early Child Development and Care, 35, 13-28.
Tagney, J. P., Baumeister, R. F., \& Boone, A. L. (2004). High SelfControl Predict Good Adjustment, Less Pathology, Better Grades, and Interpersonal Succes. Journal of Personality. Blackwell Publishing. 72 (2), 271-324.

Zora Raboteg Saric, Marija Sakic. (2014). Relation of Parenting Styles and Friendship Qualities to Self- Esteem, Life Satisfaction and Happiness in Adolescents. Applied Researches in Qualities of Life. Vol 9 (3) p 749-765.

\section{Lampiran.}

\section{Tabel 1}

Model Summary

\begin{tabular}{|c|c|c|c|c|c|c|c|c|c|}
\hline \multirow[b]{2}{*}{$\begin{array}{l}\text { Mod } \\
\text { el }\end{array}$} & \multirow[b]{2}{*}{$\mathrm{R}$} & \multirow[b]{2}{*}{$\begin{array}{l}\mathrm{R} \\
\text { Square }\end{array}$} & \multirow[b]{2}{*}{$\begin{array}{l}\text { Adjusted } \\
\text { R Square }\end{array}$} & \multirow{2}{*}{$\begin{array}{l}\text { Std. Error } \\
\text { of the } \\
\text { Estimate }\end{array}$} & \multicolumn{5}{|c|}{ Change Statistics } \\
\hline & & & & & $\begin{array}{l}\mathrm{R} \text { Square } \\
\text { Change }\end{array}$ & $\begin{array}{l}\text { F } \\
\text { Change } \\
\end{array}$ & df1 & df2 & $\begin{array}{l}\text { Sig. F } \\
\text { Change }\end{array}$ \\
\hline 1 &, $111^{\mathrm{a}}$ & ,012 & ,002 & 3,485 & ,012 & 1,206 & 1 & 97 & ,275 \\
\hline 2 &, $216^{\mathrm{b}}$ & ,047 & ,027 & 3,442 &, 034 & 3,447 & 1 & 96 & ,066 \\
\hline 3 &, $447^{\mathrm{c}}$ & ,200 & , 175 & 3,169 &, 154 & 18,252 & 1 & 95 & ,000 \\
\hline
\end{tabular}

a. Predictors: (Constant), PARENTCHILD

b. Predictors: (Constant), PARENTCHILD, PEERATTACHMENT

c. Predictors: (Constant), PARENTCHILD, PEERATTACHMENT, PXP 
Tabel 2

\begin{tabular}{|c|c|c|c|}
\hline \multicolumn{4}{|c|}{ Coefficients $^{\mathbf{a}}$} \\
\hline \multirow[b]{2}{*}{ Model } & & Standardized & \multirow[b]{2}{*}{ Sig. } \\
\hline & & Beta & \\
\hline \multirow[t]{2}{*}{1} & (Constant) & &, 000 \\
\hline & PARENTCHILD &,- 111 & ,275 \\
\hline \multirow[t]{3}{*}{2} & (Constant) & &, 000 \\
\hline & PARENTCHILD &,- 199 &, 074 \\
\hline & PEERATTACHMENT & ,205 & ,066 \\
\hline \multirow[t]{4}{*}{3} & (Constant) & &, 000 \\
\hline & PARENTCHILD & $-2,582$ &, 000 \\
\hline & PEERATTACHMENT & $-3,074$ &, 000 \\
\hline & PXP & 4,831 &, 000 \\
\hline
\end{tabular}

